\title{
A New ABS Control Strategy Designed for Electric Vehicle Independently Driven by Four Wheel Motors
}

\author{
Yu YANG \\ College of Automotive Engineering, Jilin University \\ Changchun, China \\ yy19840806@126.com
}

Li jie YANG

College of Mechanical \& Electric Engineering,

Changchun University of Science and Technology

Changchun, China

ylj1962@126.com

\author{
Shi you YANG \\ College of Mechanical and Vehicle Engineering, \\ Changchun University \\ Changchun, China \\ Ysy1957@126.com \\ Yang LIU \\ FAW Toyota Changchun Engine Co., Ltd \\ Changchun, China \\ cynthia5461@sina.com
}

\begin{abstract}
In this paper, first, a hypothesis that ABS(AntiBrake System) regulation of $\mathrm{EV}$ (Electric Vehicle) could be realized only by wheel motor was put up, then based on the logic threshold method, an ABS control strategy was designed to test this hypothesis. Furthermore, the four wheel motors directly drive EV model was created and simulated with this control strategy in AMESim, co-simulated with MATLAB/Simulink. At last, according to the ECE R13, this EV ABS control strategy was validated theoretically.
\end{abstract}

Keywords-anti-brake system; wheel motor; electric vehicle; ECE R13

\section{INTRODUCTION}

Decades before, due to the relatively slow development of vehicle motor, drive motor could not meet the requirements of the EVs directly driven by motors, and the main reason was driving torque or braking torque was too low to fulfill some extreme conditions. In order to overcame this disadvantage, usually, the wheel edge reducers were applied to driving motors to decelerate and multiply the torque [1]. Although this solution could meet the demands of basic driving in urban area, compared to conventional vehicle, the EV still fell behind in maximum speed and costs. Even though regenerative brake was contributed to fuel efficiency, when taking the braking stability and safety into consideration, most EV manufacturers still chose the hydraulic brake system as the default priority, also the hydraulic ABS products.

But as the motor technology developing rapidly, several in-wheel motor manufacturers released the high power density, high torque vehicle motor one after another, it was possible to drive or brake EVs only by in-wheel motors. For instance: In 2006, TM4 developed the electric motors used in the CITROËN C-Métisse with 300N.maximum torque and $15 \mathrm{kw}$ continuous power [2]. Debuted at the 2011 Frankfurt Motor Show, based on the Mercedes-Benz E-Class, the "Four-wheel-drive Full Electric" sedan was unveiled by BRABUS, which featured an all-new EV system developed to demonstrate a peak combined $320 \mathrm{~kW}$ and 2,350 ft.-lbs. $(3,200 \mathrm{Nm})$ torque from pure electric power using four direct-drive Protean Electric motors [3].

All data above demonstrated that as the vehicle motor technology became more mature, age of EVs was getting closer to us, meanwhile, the tendency to replace the traditional ABS with the innovative wheel motor ABS would be the mainstream of EVs. As the more powerful and accurate motor was applied to vehicle and mass production, the EVs directly driven by wheel motors were no longer stood at theoretical level, but entered every household in the future.

Therefore, based on the logic threshold method, an ABS control strategy for EVs was designed to test the hypothesis that to the four wheel motors directly drive EV, ABS regulation could be fully functioned only by torque regulation of wheel motors. Moreover, this ABS control unit, along with the four wheel motor drive EV model was modeled and co-simulated in MATLAB/Simulink with AMESim. To verify the ABS control strategy, according to ECE R13, simulation tests were carried out.

\section{CO-SIMULATION MODELING}

\section{A. AMESim Model.}

In Fig. 1, to ensure the accuracy and reality, the AMESim 15 degrees of freedom multi-body chassis model was chosen to build EV model, based on this models, AMESim vehicle model was established, added with suspension model (including spring, damper, anti-roll rod, etc.), ABS model, aerodynamic model, sensor model, tire and road model, and wheel motor model. Among them, suspension model was reinforced by elastokinematic axle model, which improved the simulation accuracy; tire model was composed by tire dynamic model, tire stiffness model, tire elastic model, tire contract point and tire sensor model, what's more, tire model parameters adopted Pacejka classic formula coefficient formula coefficient, and tire sensors acquired slip ratios directly; formula coefficient, and tire sensors acquired slip 
ratios directly; the road model included road submodel and tire contact point adherence model, the former was a simple

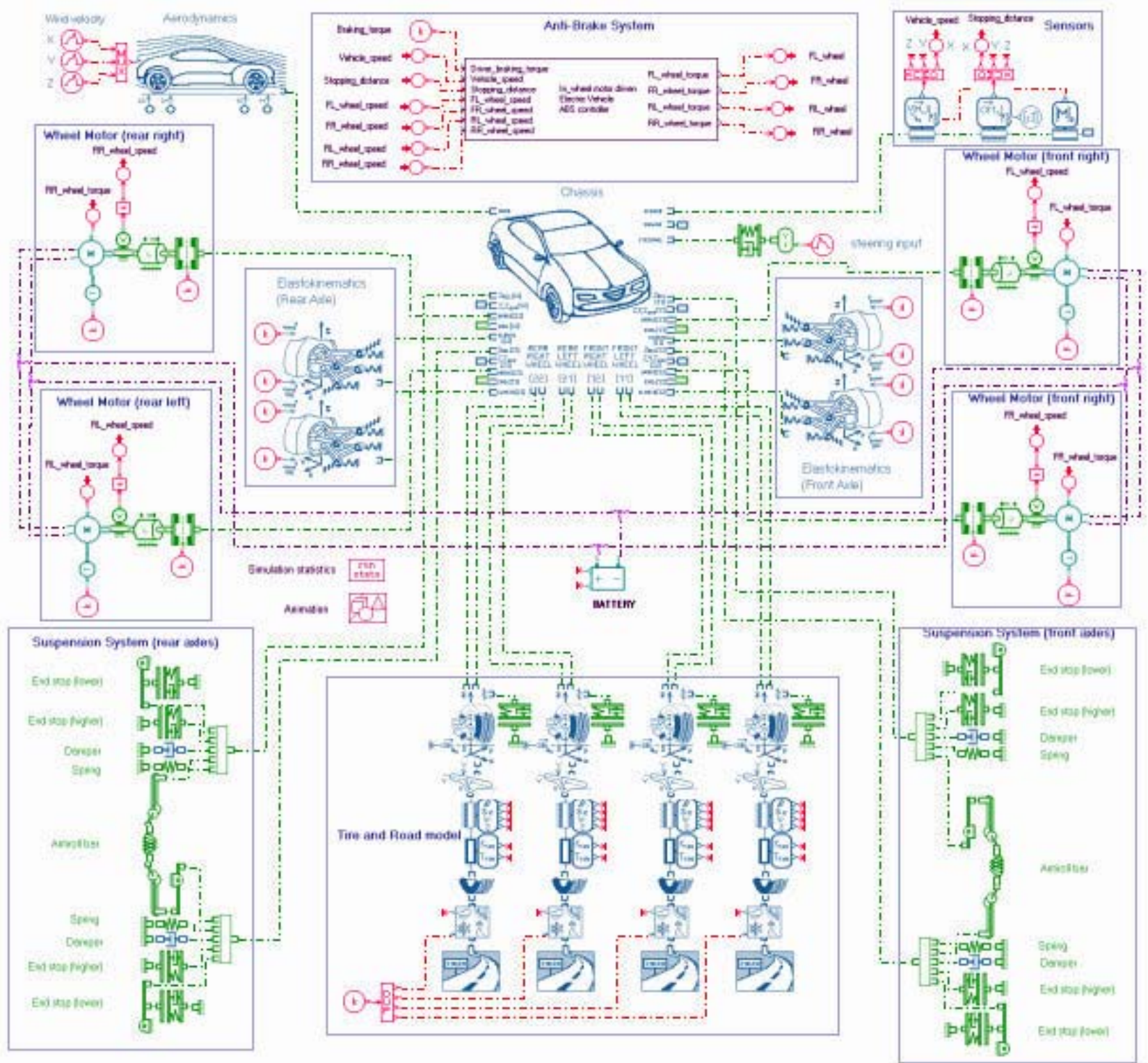

Figure 1. AMESim Four Wheel Motor Drive Electric Vehicle Model with ABS Controller.

flat road model, connected with tire contact point adherence model, the latter had the function to set road adherence coefficient [4].formula coefficient, and tire sensors acquired slip ratios directly; the road model included road submodel and tire contact point adherence model, the former was a simple flat road model, connected with tire contact point adherence model, the latter had the function to set road adherence coefficient [4]. Absolute velocity sensor and absolute displacement sensor were connected with ports of suspension sensor model, in order to obtain car body velocity and displacement. Each wheel motor was consisted of hub motor, wheel rotation speed sensor, and brake disc. Hub motor possessed maximum $2000 \mathrm{~N}^{*} \mathrm{~m}$ torque and corresponding time is approximately 0.001 second, while wheel sensor got wheel rotation speed and sent the signals to the ABS controller. ABS control strategy was complied under MATLAB/Simulink and embedded in AMESim model as a Simulinkcosim interface.

\section{B. Simulink Model.}

Vehicle model in AMESim was imported to Simulink as an S-Function, and ABS controller was build in Simulink to design the control strategy, directly connected with vehicle model. ABS control unit collected vehicle speed signals from the vehicle model, according to the required braking torque from driver and rotation speed from each wheel, the controller analyzed the signals and after that, distributed the 
actual braking torque signals to four hub motors of the EV respectively. That's how a simulation loop is finished.

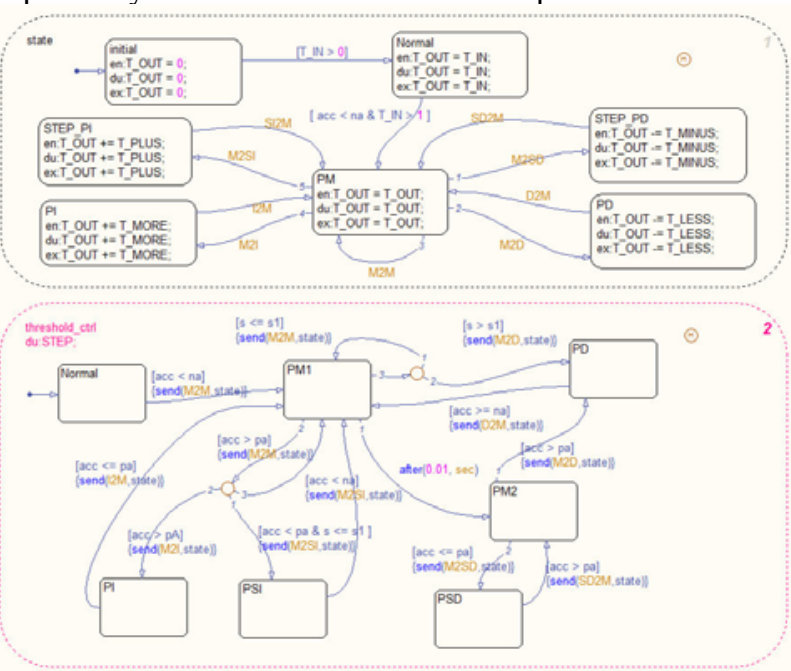

Figure 2. ABS Controller Model in MATLAB/Simulink

In Fig. 2, referred with classic logical threshold control strategy, ABS controller model was built. Inputs were each wheel speed, vehicle speed, and required brake torque, and outputs were each wheel torque. Furthermore, deceleration and slip ratio of each wheel were calculated as the control parameters: two positive wheel accelerations, one negative wheel acceleration, and one target slip ratio, chosen as the thresholds triggering the model to shift from one state to another state: braking torque increasing, braking torque maintaining and braking torque decreasing [5].

\section{Simulation Parameters.}

Due to the high cost of four wheel motor drive EV, to test our ABS controller strategy, we designed a simulation experiment procedure, and the parameters are shown below.

TABLE I. EV SIMULATION PARAMETERS

\begin{tabular}{|c|c|c|}
\hline Parameter & Value & Annotation \\
\hline $\mathrm{m}$ & $1300[\mathrm{~kg}]$ & Sprung mass \\
\hline V0 & $100[\mathrm{~km} / \mathrm{h}]$ & Vehicle speed when braking \\
\hline $\mathrm{L}$ & $2400[\mathrm{~mm}]$ & Longitudinal distance between two axle \\
\hline $\mathrm{h}$ & $375[\mathrm{~mm}]$ & Height of car body center of gravity \\
\hline $\mathrm{a}$ & $1056[\mathrm{~mm}]$ & $\begin{array}{l}\text { Longitudinal distance between car body } \\
\text { center of gravity and front axle }\end{array}$ \\
\hline $\mathrm{b}$ & $1344[\mathrm{~mm}]$ & $\begin{array}{l}\text { Longitudinal distance between car body } \\
\text { center of gravity and rear axle }\end{array}$ \\
\hline ts & 0.2 & Target slip ratio \\
\hline $\mathrm{r}$ & $300[\mathrm{~mm}]$ & Tire radius \\
\hline $\mathrm{pA}$ & $20\left[\mathrm{~m} / \mathrm{s}^{2}\right]$ & Wheel acceleration threshold $+\mathrm{A}$ \\
\hline pa & $10\left[\mathrm{~m} / \mathrm{s}^{2}\right]$ & Wheel acceleration threshold $+a$ \\
\hline na & $-60\left[\mathrm{~m} / \mathrm{s}^{2}\right]$ & Wheel deceleration threshold -a \\
\hline T_less & $20\left[\mathrm{~N}^{*} \mathrm{~m}\right]$ & Step size in torque decreasing state \\
\hline T_plus & $6\left[\mathrm{~N}^{*} \mathrm{~m}\right]$ & Step size in torque increasing state \\
\hline T_more & $8\left[\mathrm{~N}^{*} \mathrm{~m}\right]$ & Step size in torque sharply increasing state \\
\hline
\end{tabular}

\section{Simulation Results AnAlysis}

\section{A. Brake Performance Verification}

without ABS regulation by wheel motors, stopping distance is about $37.7 \mathrm{~m}$, while it reduce to $30.8 \mathrm{~m}$ when ABS functioning. At the same time, stopping time also decreases from approximately 3.35 second to 2.81 second, which both enhance EV brake performance significantly.
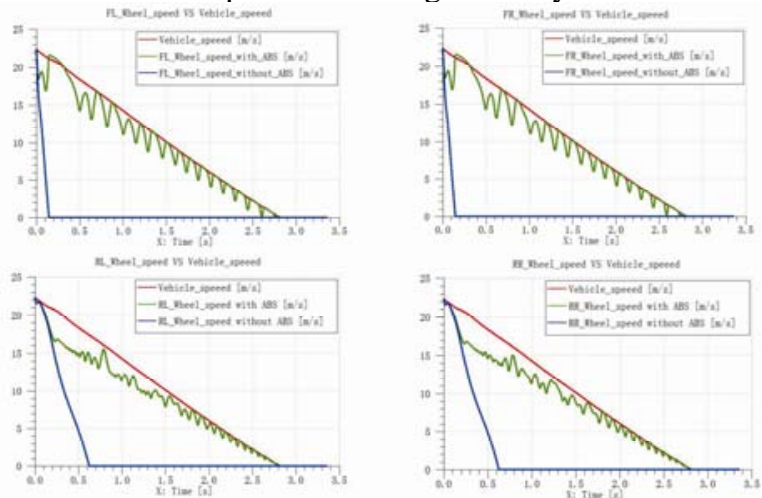

Figure 3. Wheel Speed VS. Vehicle Speed between EV with ABS regulation and that without $\mathrm{ABS}$ regulation

Fig. 3 demonstrates the four wheel speed VS. vehicle speed: without ABS regulation, the front wheel speeds drop from $80 \mathrm{~km} / \mathrm{h}$ (about $700 \mathrm{round} / \mathrm{min}$ ) to zero in just approximately 0.14 second and rear wheel speeds drop to zero in about 0.61 second, which means four wheels are locked very soon after wheels are actuated by wheel motor braking torque; but with ABS regulation, the four wheel speeds slowly decrease to zero in vehicle speed's tendency.
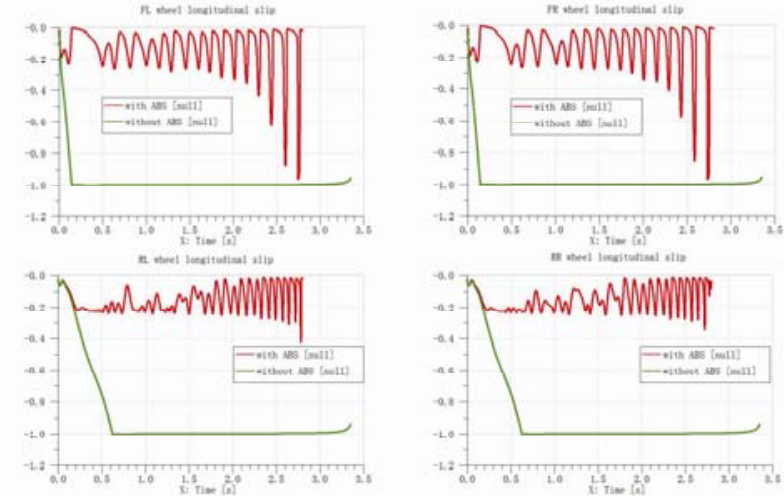

Figure 4. Wheel Longitudinal Slip Comparion between EV with ABS regulation and that without $\mathrm{ABS}$ regulation

In Fig. 4, without ABS regulation, the front and the rear wheel longitudinal slip ratios drop to -1 in about 0.14 second and about 0.61 second respectively, which represents that the wheels are locked quickly. But with ABS regulation, the four wheel longitudinal slip ratios are fluctuating around 0.2 when braking torques are applied on wheel motors. Although when around 2.4 second, longitudinal slip ratios of front wheels sharply decrease, and wheels tend to be locked, but 
according to ECE R13, when vehicle speed is lower than $15 \mathrm{~km} / \mathrm{h}$, wheel lock is permitted, and it has little effect on brake performance.
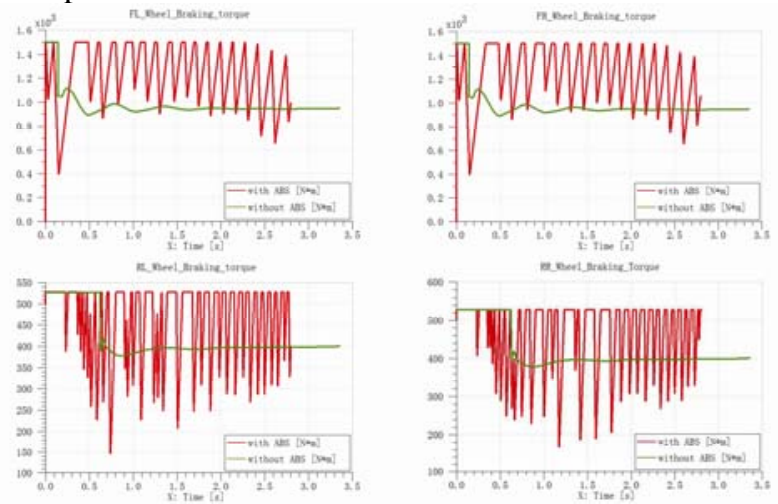

Figure 5. Wheel Braking Torque Comparion between EV with ABS regulation and that without $\mathrm{ABS}$ regulation

Lastly, in Fig. 5, without ABS regulation, braking torques decrease sharply soon after the wheel motors actuate wheels to brake, also the braking torque can not maintain at the maximum level. But with ABS regulation, braking torques are adjusted according to wheel deceleration and slip, to make sure no wheel is locked, high braking torque and adherence utilization.

To sum up, wheel motor ABS regulation achieves the same result of the traditional ABS regulation: wheel lock is avoided and braking torque is fully utilized. Brake performance is also improved.

\section{B. Rules Verification.}
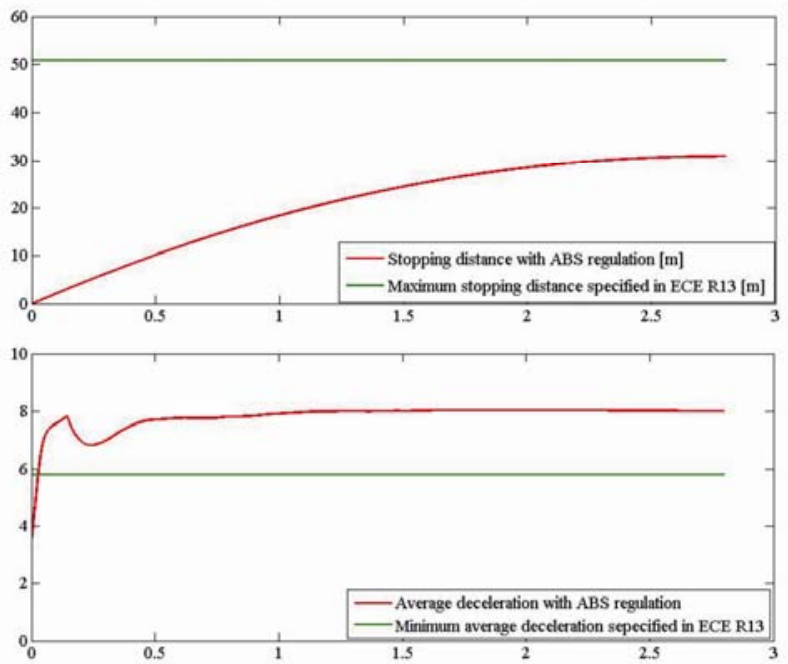

Figure 6. Stopping Distance and Average Deceleration Verification based on rule ECE R13
Showed in Fig. 8, similar to FMVSS135 and other rules, the rule ECE R13 also evaluate the brake system through measuring two important parameters: the stopping distance and the average deceleration [6]. According to ECE R13 [7], when vehicle brake at the speed of $80 \mathrm{~km} / \mathrm{h}$, stopping distance must be less than $37.2 \mathrm{~m}$, and average deceleration must be more than $5.8 \mathrm{~m} / \mathrm{s}^{2}$. To verify the control strategy designed in this paper, two special modules were added into the Simulink model to measure the stopping distance and average deceleration, at the same time, make the comparison. The results above fully proved that this novel ABS control strategy fit for four wheel motor drive EV and meet the requirements of ECE R13.

\section{SUMMARY}

Based on the features of wheel motor: rapid response, instant high torque, and wide speed range, etc., a new ABS control strategy was design in this paper, which directly regulate the wheel motor torque to achieve the function of ABS properly. Besides, all the simulation results illustrated that for four wheel motor independently drive EVs, the ABS regulated by wheel motor was a promising design, and improved brake performance significantly, also conformed to ECE R13. With sufficient hardware to back up, it is not far from us that this ABS control unit will go into mass production and all wheel motor drive EVs are equipped with the ABS[8].

\section{REFERENCES}

[1] P. E. Wellstead and N. B. O. L. Pettit, in: Analysis and redesign of an antilock brake system controller, IEE Proceedings of Control Theory nd Applications, vol. 144, no. 5, pp. 413-426, September 1997.

[2] Information on http://www.tm4.com/en/electric_corner_module.aspx

[3] Information http://www.proteanelectric.com/?page_id=158\&post=1017

[4] Information on http://www.lmsintl.com/vehicle-system-dynamics

[5] L. Si, in: Antiskid System in Automobile: ABS \& ASR, Beijing: China Communications Press, 1997.

[6] Y.P. He, J,G, Lun, in: Overview of Domestic and Overseas Passenger Car Brake Rules, volume 3 of Automotive Engineering, ISSN 1000680X (1994).

[7] Information on http://www.unece.org/fileadmin/DAM/trans/doc/2004/wp29grrf/TRA NS-WP29-GRRF-56-inf03e.pdf

[8] Christian von Albrichsfeld, Jurgen Karner, "Brake System for Hybrid and Electric Vehicles,” SAE 2009-01-1217 